\title{
1 An improved description of the interactions between rare earth \\ 2 \\ 3 \\ elements and humic acids by modeling: \\ PHREEQC-Model VI coupling
}

4

5

6

7

8

9

10

11

12

13

14

15

16

17

18

19

20

21

22

23 *Corresponding author: Tel +33 223235 395; Fax: +33 223236090

24 E-mail address: remi.marsac@univ-rennes1.fr

25

Rennes Cedex, France

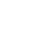

(1)

(1)

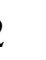

3

(4)

5

6

7

8

9

20

21

22

Rémi Marsac*, Mélanie Davranche, Gérard Gruau, Martine Bouhnik-Le Coz and Aline Dia

Geosciences Rennes, UMR CNRS - 6118, University of Rennes 1, Campus Beaulieu, 35042

$-1-$ 
Abstract- The Humic Ion Binding Model VI (Model VI) - previously used to model the equilibrium binding of rare earth elements (REE) by humic acid (HA) - was modified to account for differences in the REE constant patterns of the HA carboxylic and phenolic groups, and introduced into PHREEQC to calculate the REE speciation on the HA binding sites. The modifications were shown to greatly improve the modeling. They allow for the first time to both satisfactorily and simultaneously model a large set of multi-REE experimental data with the same set of equations and parameters. The use of PHREEQC shows that the light rare earth elements (LREE) and heavy rare earth elements (HREE) do not bind to HA by the same functional groups. The LREE are preferentially bound to carboxylic groups, whereas the HREE are preferentially bound to carboxy-phenolic and phenolic groups. This binding differentiation might lead to a fractionation of REE-HA patterns when competition between REE and other metals occur during complexation. A survey of the available data shows that competition with $\mathrm{Al}^{3+}$ could lead to the development of HREE-depleted HA patterns. This new model should improve the hydrochemical modeling of the REE since PHREEQC takes into account chemical reactions such as mineral dissolution/precipitation equilibrium and redox reactions, but also models kinetically controlled reactions and one-dimensional transport.

Keywords: rare earth elements, humic acid, complexation, modeling, PHREEQC, Model VI, site heterogeneity.

\section{INTRODUCTION}

Dissolved humic acids (HA) are complex macro-molecules that contain a large variety of functional groups giving rise to strong binding capacities with cations. Because of HA $-2-$ 
ubiquity, a lot of effort has been made in the past 20 years to set up thermodynamic models that are suitable for predicting cation complexation by HA in natural waters (Marinsky and Ephraim, 1986; Tipping and Hurley, 1992; Koopal et al., 1994; Kim and Czerwinski, 1996; Tipping, 1998; Sasaki et al., 2008). The two major types of HA-cation binding surface groups are the carboxylic and phenolic groups. Each type covers a large range of cation stability constants $(\log \mathrm{K})$. The two most used cation-HA binding models are Model VI (Tipping, 1998), in which both the carboxylic and phenolic groups are discrete entities displaying specific stability constants, and NICA-Donnan (Kinniburgh et al., 1996), in which continuous distributions of $\log \mathrm{K}$ are considered. In both models, the variety of the HA binding sites is taken into account, as the $\log \mathrm{K}$ distribution is calculated from the cation-carboxylic and cation-phenolic specific binding parameters. By fitting the datasets for each of these two models, Tipping (1998) and Milne et al. (2003) were able to determine the generic HA binding parameters for a wide variety of cations. They found that cation-phenolic model parameters can be mathematically correlated to cation-carboxylic parameters. These mathematical correlations are very useful to estimate phenolic binding parameters from carboxylic binding parameters, notably when experimental data are limited or non-existent. For Model VI, Tipping (1998) chose to impose a linear relationship between the carboxylic and phenolic cation binding parameters (log $\mathrm{K}_{\mathrm{MA}}$ and $\log \mathrm{K}_{\mathrm{MB}}$, respectively). Thus, only one parameter has to be adjusted in order to describe the interaction of cations with humic acids using Model VI, i.e. Log $\mathrm{K}_{\mathrm{MA}}$.

Rare earth elements (REE) are a highly coherent series of elements, whose chemical properties vary regularly along the series. Their relative affinity for ligands can be visualized in the plot of the intrinsic stability constants $(\log \mathrm{K})$ or the partition coefficient between two phases $\left(\log \mathrm{K}_{\mathrm{d}}\right)$ versus the REE atomic number. Different and specific shapes of $\log \mathrm{K}$ -3 - 
patterns are therefore displayed depending on the ligands (Byrne and Li, 1995). Moreover, the REE are particularly suitable to study cation-HA interactions. Experimental and field studies showed that when HAs are present in natural waters, most of the REE occur as REE-HA complexes (Bidoglio et al., 1991; Takahashi et al., 1997; Viers et al., 1997; Dia et al., 2000; Tang and Johannesson, 2003; Johannesson et al., 2004; Gruau et al., 2004; Davranche et al., 2005; Sonke and Salters 2006; Pourret et al., 2007a, b; Pédrot et al., 2008). Recent experimental studies on REE-HA binding have shown that the metal loading (REE/HA) can modify the REE partitioning between an aqueous solution and HA (Marsac et al., 2010; Yamamoto et al., 2010). At high loading, a middle-REE (MREE) downward concavity, typical of REE binding to low affinity carboxylic sites, was observed. However, under low REE/HA conditions, the $\log \mathrm{K}_{\mathrm{d}}$ pattern exhibited a regular increase from $\mathrm{La}$ to $\mathrm{Lu}$, which is typical of REE binding to strong affinity multidentate sites (Marsac et al., 2010; Yamamoto et al., 2010). These two types of $\log \mathrm{K}_{\mathrm{d}}$ patterns correspond to the $\log \mathrm{K}$ patterns obtained for the corresponding simple organic ligands (namely acetic acid for the carboxylic sites, and EDTA for the multidentate sites). Their successive occurrence is plausible since the site density of the HA high affinity sites is much lower than the density of the low affinity sites. Marsac et al. (2010) showed that in order to properly model this data with Model VI, it was necessary to let the parameter accounting for the high affinity sites, $\Delta \mathrm{LK}_{2}$, vary among the REE series instead of keeping it constant, as commonly assumed. However, although there is a good agreement between the experimental and modeled data, the HA sites defined in Model VI are still not fully satisfactory for the REE series. The assumption of a similar log K pattern shape for the carboxylic and phenolic sites, imposed by the $\log \mathrm{K}_{\mathrm{MA}}$-Log $\mathrm{K}_{\mathrm{MB}}$ linear relationship, is not consistent with the $\log \mathrm{K}$ pattern observed for the REE-catechol complex an analog of phenol - which exhibits a regular increase in heavy-REE (HREE) log K values -4 - 
(IUPAC, Stability Constants Database). Because phenolic sites have a lower acidic constant $\left(\mathrm{K}_{\mathrm{a}}\right)$ than carboxylic sites and occur in lower density (Ritchie and Perdue, 2003), their $\log \mathrm{K}$ pattern could theoretically be directly determined by performing REE-HA binding experiments at $\mathrm{pH}>7$ and low $\mathrm{REE} / \mathrm{HA}$ ratios. However, these kinds of experiments are technically hard to perform with regard to the low aqueous REE concentration imposed by the pH values. Marsac et al. (2010) and Yamamoto et al. (2010) therefore carried out their experimental studies at a low pH (3 and 4.7, respectively) in order to be able to measure the REE aqueous concentration at low REE/HA ratios. Pourret et al. (2007b) explored higher pH values (up to 10.5), but the high imposed REE/HA ratio prevented the study of the phenolic $\log \mathrm{K}$ patterns. This problem might be circumvented by studying REE-HA binding through competition ligand experiments with EDTA, as previously done by Sonke and Salters (2006). However, as stated by Yamamoto et al. (2010), the increasing log K(REE-EDTA) values from La to Lu implies that each REE binding is not studied at the same metal loading, thereby preventing the comparison of the log $\mathrm{K}$ patterns with the patterns for the conditional stability constants.

In this study, a modeling approach was used to evaluate whether the HA phenolic sites differ from the HA carboxylic sites in their ability to complex REE. The stability constants of the REE-HA phenolic sites were thus independently estimated. For this purpose, Model VI equations were introduced into PHREEQC (Parkhurst and Appelo, 1999), following Liu et al. (2008). The PHREEQC/Model VI model was then used to fit the HA-REE binding datasets published by Sonke and Salters (2006), Pourret et al. (2007b) and Marsac et al. (2010). 


\section{MATERIALS AND METHODS}

119

122

123

124

125

126

127

128

130

131

132

133

134

135

136

137

138

139

140

\subsection{Humic Ion binding Model VI}

The humic-ion binding Model VI was developed by Tipping (1998) and introduced into the WHAM 6 program. A thorough description of Model VI can be found in Tipping (1998). The model is a discrete binding site model which takes electrostatic interactions into account. Eight sites are considered and divided into an equal number of type A sites (the weak acidic sites, commonly associated with carboxylic functional groups) and type B sites (the strong acidic sites, commonly associated with phenolic functional groups). There are $\mathrm{n}_{\mathrm{A}}$ (mol $\left.\mathrm{g}^{-1}\right)$ type A sites and $\mathrm{n}_{\mathrm{A}} / 2$ type B sites. Proton binding is described by the two median intrinsic constants $\left(\mathrm{pK}_{\mathrm{A}}\right.$ or $\left.\mathrm{pK} \mathrm{K}_{\mathrm{B}}\right)$ and two parameters defining the spread of the equilibrium constants around the median $\left(\Delta \mathrm{pK}_{\mathrm{A}}\right.$ or $\left.\Delta \mathrm{pK}_{\mathrm{B}}\right)$. The intrinsic equilibrium constants for cation binding are defined by two median constants $\left(\log \mathrm{K}_{\mathrm{MA}}\right.$ and $\left.\log \mathrm{K}_{\mathrm{MB}}\right)$, together with parameters $\left(\Delta \mathrm{LK}_{1 \mathrm{~A}}\right.$ and $\left.\Delta \mathrm{LK}_{1 \mathrm{~B}}\right)$ that define the spread of the values around the medians. By considering the results from many datasets, a universal average value of $\Delta \mathrm{LK}_{1}$ was obtained for all cations (2.8) and a linear relationship was established between the $\log \mathrm{K}_{\mathrm{MB}}$ and $\log \mathrm{K}_{\mathrm{MA}}$ parameters (Tipping, 1998):

$$
\log \mathrm{K}_{\mathrm{MB}}=3.39 \times \log \mathrm{K}_{\mathrm{MA}}-1.15 \text { (Eq. 1) }
$$

Therefore, only one single adjustable parameter $\left(\log \mathrm{K}_{\mathrm{MA}}\right)$ is necessary to describe metal complexation by HA in Model VI. In Model VI, cations first hydrolysis products (e.g. $\mathrm{LaOH}^{2+}$ ) are also considered to bind to HA with the same parameters than the corresponding aquo ions.

Some of the type A and type B monodentate sites can form bi- and tridentate sites. The stability constants of these bi- and tridentate sites are defined by the sum of the $\log \mathrm{K}$ values $-6-$ 
141 of the monodentate sites of which they are constituted. Cation-HA binding can occur through

142 carboxylic groups (CG), carboxy-phenolic groups (CPG) or phenolic groups (PG). A small

143 part of the stability constants of multidentate groups are increased by the $\Delta \mathrm{LK}_{2}$ parameter, the

144 so-called "strong binding site term" (Tipping, 1998). $\Delta \mathrm{LK}_{2}$ is attributed to both favorable

145 spatial arrangements of the ligands, which stabilizes the complex, and to the chelate effect or

146 participation of ligands, such as the nitrogen-containing groups. $\Delta \mathrm{LK}_{2}$ is the parameter of the

147 HA site heterogeneity. An elevation of $\Delta \mathrm{LK}_{2}$ increases the range of the stability constants

148 covered by the HA sites, thus increasing the heterogeneity of the HA sites. The total

149 heterogeneity of the HA surface sites in Model VI is defined by 80 different sites.

150 An electrical double layer, where only counter-ions can accumulate, is defined. The

151 double layer thickness is set by the Debye-Hückel parameter $\kappa$. The distribution of ions

152 between the diffuse layer and the bulk solution is calculated by a simple Donnan model. The

153 Donnan volume $\left(\mathrm{V}_{\mathrm{D}}\right)$ is the volume adjacent to the surface. The electrostatic correction is

154 represented by an empirical equation which mimics the Boltzmann factor:

$155 \quad \operatorname{Exp}(-\mathrm{zF} \psi / \mathrm{RT})=\exp \left(-2 \mathrm{PzZ} \log _{10} \mathrm{I}\right)(\mathrm{Eq} .2)$

156 where $\mathrm{P}$ is an adjustable parameter, $\mathrm{z}$ is the ion charge, $\mathrm{Z}$ is the net humic acid charge

$157(\mathrm{eq} / \mathrm{g}), \mathrm{I}$ is the ionic strength $\left(\mathrm{mol} \mathrm{L}^{-1}\right), \psi$ is the surface potential $(\mathrm{V}), \mathrm{T}$ is the temperature $(\mathrm{K})$,

$158 \mathrm{~F}$ is the Faraday constant and $\mathrm{R}$ is the gas constant. The Model VI parameters used in the 159 present study are summarized in Table 1.

\subsection{PHREEQC/Model VI coupling}

PHREEQC is based on an ion-association aqueous model and was designed to perform speciation and saturation-index calculations (Parkhurst and Appelo 1999). The cation-HA

163 binding reaction with the 80 types of HA sites defined in Model VI was written and -7 - 
164 introduced into the PHREEQC "minteq.v4" database. Before removing the constraint

165 imposed by the linear relationship between $\log \mathrm{K}_{\mathrm{MA}}$ and $\log \mathrm{K}_{\mathrm{MB}}$, a first version of 166 PHREEQC/Model VI using the equations defined in WHAM 6/Model VI was tested for its 167 ability to give identical results to WHAM 6/Model VI. Humic acid was defined as the 168 SOLUTION_MASTER_SPECIES, SOLUTION_SPECIES and PHASES in the "minteq.v4" 169 database. The 80 types of sites considered by Model VI were defined as the 170 SURFACE_MASTER_SPECIES, and their respective stability constants as the 171 SURFACE SPECIES in the "minteq.v4" database. This procedure is similar to that used 172 previously by Liu et al. (2008) to model the binding of Eu by HA in clay pore water using the 173 same PHREEQC-Model VI combination, except that in this study, we used $\Delta \mathrm{LK}_{2}$ values $\neq 0$.

174 Therefore, the 80 binding sites defined by Tipping (1998) are taken into account versus only 17532 sites in Liu et al. (2008). In order to model similar REE binding by each specific HA sites 176 with WHAM 6/Model VI and PHREEQC/Model VI, REE-HA binding simulations were 177 compared with the corresponding REE-simple ligands complexes in solution. The results 178 obtained differed between both models. The $\Delta \mathrm{LK}_{1}$ parameter $(=2.8)$ should actually be 179 defined as $\Delta \mathrm{pK}_{\mathrm{A}}-\Delta \mathrm{LK}_{1 \mathrm{~A}}$, for carboxylic groups, and as $\Delta \mathrm{pK}_{\mathrm{B}}-\Delta \mathrm{LK}_{1 \mathrm{~B}}$, for phenolic groups 180 (i.e. $\Delta \mathrm{LK}_{1 \mathrm{~A}}=-0.7$ and $\Delta \mathrm{LK}_{1 \mathrm{~B}}=0.8$ ). In order to model the non-specific binding in a similar 181 fashion (i.e. ions accumulated around HA molecules by electrostatic attraction) as well as the 182 electrostatic correction in WHAM 6/Model VI and PHREEQC/Model VI, the Gouy-Chapman 183 type double layer defined in PHREEQC was coupled with a Donnan phase, excluding the 184 presence of co-ions. The Debye-Hückel parameter $\kappa$ was calculated from the relationship: $\kappa=$ 185 (3.29 x $\left.10^{9} \times \mathrm{I}^{1 / 2}\right)^{-1}$ (Appelo and Postma, 2005). In PHREEQC, the surface area (SA), upon 186 which the Boltzmann factor depends, is an adjustable parameter. Marsac et al. (2010) $-8-$ 
determined Model VI REE-HA specific binding parameter with $\mathrm{P}=-330$. To satisfy equation

188 2, the PHREEQC SA was simply determined by fitting the HA surface charge (QwHAm in eq $189 \mathrm{~g}^{-1}$ ) generated by WHAM 6/Model VI as a function of $\mathrm{pH}$, at varied $\mathrm{NaCl}$ concentrations and

$19010 \mathrm{mg}$ of HA. The best fit was obtained for a SA equal to 40000,19000 and $13000 \mathrm{~m}^{2} \mathrm{~g}^{-1}$ at 191 an ionic strength 0.001, 0.01 and 0.1, respectively. By this method we found QPHREEQC $=0.92$

$192 \times \mathrm{Q}_{\text {WHAM }}+310^{-4}\left(\mathrm{R}^{2}=1\right)$. Since SA decreases with $\mathrm{P}$, our results are consistent with those of 193 Liu et al. (2008) who determined $\mathrm{SA}=30000 \mathrm{~m}^{2} \mathrm{~g}^{-1}$ at an ionic strength of $0.015 \mathrm{~mol} \mathrm{~L}^{-1}$ and $194 \quad \mathrm{P}=-120$.

\subsection{Experimental data}

Three datasets were used to calibrate the PHREEQC/Model VI parameters for REE binding to HA (Sonke and Salters, 2006; Pourret et al., 2007b; Marsac et al., 2010). These datasets were preferentially chosen because they provide data for the entire REE group and they covered a large range of $\mathrm{pHs}$, metal loading and organic ligand competition. The experimental conditions of the three datasets used are given below.

\subsubsection{Pourret et al's. dataset (2007b)}

Pourret et al. (2007b) performed REE-HA binding experiments for the 14 REE simultaneously over pHs ranging from 2 to 10.5 at an ionic strength (IS) of $10^{-3} \mathrm{M}$. The HA used was purified Aldrich Humic Acid. The experiments were performed with $50 \mathrm{ppb}$ of each REE at three HA concentrations: 5, 10 and $20 \mathrm{mg} \mathrm{L}^{-1}\left(510^{-3}<\mathrm{REE} / \mathrm{HA}<210^{-2} \mathrm{~mol} \mathrm{REE} / \mathrm{mol}\right.$ C). The separation of HA from the inorganic complexes was performed by ultrafiltration. The REE concentrations were measured by Inductively Coupled Plasma Mass Spectrometry (ICPMS). The results showed an increase in the REE-HA binding with increasing $\mathrm{pH}$ and 
increasing HA concentrations. The log K REE-HA pattern is marked by a downward, MREE

210 concavity. These data therefore provide a dataset for REE-HA binding at high metal loading

211 and over a large $\mathrm{pH}$ range where the REE are bound to HA by carboxylic or phenolic sites,

212 depending on the $\mathrm{pH}$. Note however, that the data at $\mathrm{pH}>7$ were not considered in the model 213 calibration, since $100 \%$ of the REE were bound to HA in Pourret et al. (2007b), making the 214 data useless for the calibration of the model.

\subsubsection{Marsac et al.'s dataset (2010)}

Marsac et al. (2010) used Pourret et al.'s method (2007b) to study the metal loading

217 effect on REE binding to HA $\left(410^{-4}<\mathrm{REE} / \mathrm{HA}<2.710^{-2} \mathrm{~mol} \mathrm{REE} / \mathrm{mol} \mathrm{C}\right)$. In order to obtain

218 measurable REE concentrations in the solution, Marsac et al. (2010) performed all their 219 experiments under acidic conditions $(\mathrm{pH}=3)$. The ionic strength was fixed at $10^{-2} \mathrm{M}$. Marsac et al. (2010) observed an increase in the REE-HA binding and a change in the log K REE-HA pattern with decreasing metal loading. At high metal loading, the log K REE-HA pattern exhibited a MREE-downward concavity and at low metal loading, a regular increase from La to $\mathrm{Lu}$ was observed. These data therefore provide an REE-HA complexation dataset at 224 variable metal loading under acidic pH conditions. At pH 3 and low metal loading, the REE 225 are bound to HA by low density strong multidentate sites, whereas at high loading, the REE 226 are primarily bound to high density weak sites.

\subsubsection{Sonke and Salters' dataset (2006)}

Sonke and Salters (2006) performed REE-HA binding experiments for each REE 229 separately. The HA used was purified Leonardite HA. These authors used EDTA as a 230 competitive ligand of HA for the REE. The experiments were carried out at low metal loading $-10-$ 
231 (2 $10^{-4} \mathrm{~mol} \mathrm{REE} / \mathrm{mol} \mathrm{C}$ ), slightly acidic to basic $\mathrm{pH}$ (6 to 9 ) and an IS $=0.1 \mathrm{M}$. The separation 232 and measurement of the EDTA-REE and HA-REE complexes were done by capillary 233 electrophoresis coupled with ICP-MS. This study provides single REE-HA binding data for 234 high $\mathrm{pH}$ and low metal loading, two conditions that cannot be obtained by the methods 235 developed by Pourret et al. (2007b) and Marsac et al. (2010). To simulate Sonke and Salters' 236 experiments (2006), EDTA was introduced into the PHREEQC “minteq.v4" database as the 237 SOLUTION_MASTER_SPECIES and SOLUTION_SPECIES. The four EDTA protonation 238 constants and the fourteen REE-EDTA stability constants for IS $=0$ given in Sonke and 239 Salters (2006) were also introduced as the SOLUTION_SPECIES.

\subsection{Modeling strategy}

Linear free energy relationships (LFER) are commonly used to determine the cation-

242 HA binding parameters (Tipping, 1998). This method was used by several authors to estimate

243 the $\log \mathrm{K}_{\mathrm{MA}}$ parameter in Model VI (or the previous version, Model V) in order to describe 244 the REE-HA binding (Tang and Johannesson, 2003; Sonke, 2006; Pourret et al., 2007b). In 245 particular, Tang and Johannesson (2003) and Pourret et al. (2007b) demonstrated that REE246 HA binding could be reasonably well modeled by using the existing LFER between $\log \mathrm{K}_{\mathrm{MA}}$ $247\left(\mathrm{pK}_{\mathrm{MA}}\right.$ in Model V) and $\log \mathrm{K}$ for metal complexation by acetic acid. However, Marsac et al. 248 (2010) demonstrated that $\log \mathrm{K}_{\mathrm{MA}}$ for the HREE are lower than those estimated by LFER 249 when $\log \mathrm{K}_{\mathrm{MA}}$ and $\Delta \mathrm{LK}_{2}$ were optimized simultaneously. The decrease in $\log \mathrm{K}_{\mathrm{MA}}$ 250 compensates for the high $\Delta \mathrm{LK}_{2}$ values obtained for the HREE. Here, the new REE $\log \mathrm{K}_{\mathrm{MA}}$ 251 were optimized, thus keeping a linear relationship with $\log \mathrm{K}_{\mathrm{MA}}$ reported in Marsac et al. 252 (2010). This method allows preserving the same pattern. Log $K_{M A}$, the REE-HA carboxylic 253 binding parameter, mainly influences the calculation of REE-HA binding at acidic to neutral $-11-$ 
254 pHs since the carboxylic groups have high proton dissociation constants. Therefore, the log $255 \mathrm{~K}_{\mathrm{MA}}$ values were first optimized by fitting the "acidic" experimental data from Pourret et al. 256 (2007b) and Marsac et al. (2010).

$\log \mathrm{K}_{\mathrm{MB}}$ represents the binding parameter for the HA phenolic groups. However, no stability constants are currently available for REE complexation by phenol. Therefore, 259 catechol was used as an analog. A linear relationship was applied between the $\log \mathrm{K}$ values 260 for REE-catechol (IUPAC stability constant database) and $\log \mathrm{K}_{\mathrm{MB}}$ in order to impose a 261 phenolic-type pattern onto $\log \mathrm{K}_{\mathrm{MB}}$. Because phenolic groups have low acidic constants $(\mathrm{Ka})$, 262 the influence of $\log \mathrm{K}_{\mathrm{MB}}$ on REE-HA binding is mainly observed at neutral to basic pHs. 263 Therefore, $\log \mathrm{K}_{\mathrm{MB}}$ was optimized by fitting the data of Sonke and Salters (2006).

As already stated, $\Delta \mathrm{LK}_{2}$ represents the HA heterogeneity parameter or the strong 265 binding site term of Model VI. $\Delta \mathrm{LK}_{2}$ indicates the presence of multidentate sites, whose 266 affinity for REE increases from $\mathrm{La}$ to $\mathrm{Lu}$ (Byrne and Li, 1995; Sonke and Salters, 2006; 267 Pourret et al., 2007b; Marsac et al., 2010). Tipping (1998) suggests that the $\Delta \mathrm{LK}_{2}$ parameter is 268 similar for the carboxylic and phenolic multidentate sites. However, preliminary experimental 269 data fitting, carried out during the course of this study, showed that the three datasets used to 270 optimize the HA binding parameters could not be satisfactorily modeled, except when using 271 different $\Delta \mathrm{LK}_{2}$ values for the carboxylic and phenolic sites. In the same way that 272 PHREEQC/Model VI allows independent $\log \mathrm{K}_{\mathrm{MA}}$ and $\log \mathrm{K}_{\mathrm{MB}}$ optimization, it also allows 273 different $\Delta \mathrm{LK}_{2}$ values to be ascribed to the multidentate sites depending on their composition 274 in carboxylic $\left(\Delta \mathrm{LK}_{2 \mathrm{C}}\right)$ or phenolic $\left(\Delta \mathrm{LK}_{2 \mathrm{P}}\right)$ sites. Note that the strong binding site terms of the 275 carboxylic-phenolic multidentate sites are calculated as the $\Delta \mathrm{LK}_{2 \mathrm{C}}$ and $\Delta \mathrm{LK}_{2 \mathrm{P}}$ weighted 276 average, depending on the chemical composition of the sites. Because the density of the $-12-$ 
multidentate sites is low at the surface of HA, their control on REE binding occurs mainly under low metal loading conditions, and under low and high $\mathrm{pH}$ conditions for the carboxylic and phenolic sites, respectively. Consequently, $\Delta \mathrm{LK}_{2 \mathrm{C}}$ optimization was first performed with Marsac et al.'s data (2010) and $\Delta \mathrm{LK}_{2 \mathrm{P}}$ optimization with Sonke and Salters' data (2006). Both $\Delta \mathrm{LK}_{2 \mathrm{C}}$ and $\Delta \mathrm{LK}_{2 \mathrm{P}}$ were constrained to increase progressively from $\mathrm{La}$ to $\mathrm{Lu}$ due to a linear correlation between the new $\Delta \mathrm{LK}_{2 \mathrm{C}}$ and $\Delta \mathrm{LK}_{2 \mathrm{P}}$ and the $\Delta \mathrm{LK}_{2}$ previously reported by Marsac et al. (2010).

Errors between the experimental data and the calculations were quantified by the root mean square error of the regression (rmse), i.e. the sum of the squares of the differences between the observed and calculated $\log v$, where $v$ is the amount of REE bound to HA per gram of dissolved organic carbon (DOC). The fit was considered as being good when the total rmse calculated from the whole REE and experimental conditions was low and when the rmse values for each REE were close to each other. The modeling strategy here above described shows that some of WHAM 6/Model VI constrains on parameters were suppressed only to introduce other comparable constrains. Therefore, WHAM 6/Model VI and PHREEQC/Model VI fit goodness can be compared directly with rmse since the degree of freedom does not significantly varies from a model to another.

\section{RESULTS}

\subsection{Modeling parameters}

The new REE-HA binding parameters were obtained from the combination of PHREEQC/Model VI and the assumptions and strategy described above. They were adjusted until a reasonable fit - quantified by the rmse - was reached. The results are presented in Table 
2. In Figure 1, they are compared with the REE-HA binding parameters obtained by Marsac 300 et al. (2010) with WHAM 6/Model VI and the corresponding model ligands (i.e. acetic acid 301 for $\log \mathrm{K}_{\mathrm{MA}}$ and catechol for $\log \mathrm{K}_{\mathrm{MB}}$ ). The following equations for the linear relationships

302

303

304

305

306

307

308

309

310

311

312

313

314 were used to determine the REE-HA specific binding parameters with PHREEQC/Model VI:

$$
\begin{array}{ll}
\log \mathrm{K}_{\mathrm{MA}}=2.12 \times \log \mathrm{K}_{\mathrm{MA}}(1)-2.44 & \left(\mathrm{R}^{2}=0.98\right) \\
\log \mathrm{K}_{\mathrm{MB}}=0.37 \times \log \mathrm{K}(\mathrm{REE} \text {-catechol })+0.86 & \left(\mathrm{R}^{2}=0.95\right) \\
\Delta \mathrm{LK}_{2 \mathrm{C}}=0.26 \times \Delta \mathrm{LK}_{2}(1)+1.74 & \left(\mathrm{R}^{2}=0.97\right) \\
\Delta \mathrm{LK}_{2 \mathrm{P}}=0.72 \times \Delta \mathrm{LK}_{2}(1)+3.60 & \left(\mathrm{R}^{2}=1\right)
\end{array}
$$

where $\log \mathrm{K}_{\mathrm{MA}}(1)$ and $\Delta \mathrm{LK}_{2}(1)$ refer to the $\log \mathrm{K}_{\mathrm{MA}}$ and $\Delta \mathrm{LK}_{2}$ values determined by Marsac et al. (2010).

The removal of the constraint imposed by the linear relationship between log $\mathrm{K}_{\mathrm{MA}}$ and $\log \mathrm{K}_{\mathrm{MB}}$ in WHAM6/Model VI and the use of REE-catechol binding parameters results in a significant increase of the $\log \mathrm{K}_{\mathrm{MA}}$ values (3.29 versus 2.7, on average, in Marsac et al. 2010). By contrast, the $\log \mathrm{K}_{\mathrm{MB}}$ values are greatly reduced: from 8.02 to 4.93, on average, in Marsac et al. (2010) and as reported in this study, respectively. The $\log \mathrm{K}_{\mathrm{MB}}$ values produced independently with PHREEQC/Model VI are very different from the log $\mathrm{K}_{\mathrm{MB}}$ values calculated with the $\log \mathrm{K}_{\mathrm{MB}}-\log \mathrm{K}_{\mathrm{MA}}$ linear correlation established by Tipping (1998) in WHAM6/Model VI (Eq. 1). The present $\log \mathrm{K}_{\mathrm{MA}}$ and $\log \mathrm{K}_{\mathrm{MB}}$ are not related to each other by a linear correlation, but their relative order of magnitude order is preserved, $\log \mathrm{K}_{\mathrm{MB}}>\log$ $\mathrm{K}_{\mathrm{MA}}$. Tipping (1998) obtained values of $\log \mathrm{K}_{\mathrm{MA}}(\mathrm{Eu})=3.09$ and $\log \mathrm{K}_{\mathrm{MB}}(\mathrm{Eu})=5.33$, when they independently optimized the $\log \mathrm{K}_{\mathrm{MA}}$ and $\log \mathrm{K}_{\mathrm{MB}}$ values for Eu during the construction of Model VI. These values are close to the values obtained here in this study: $\log \mathrm{K}_{\mathrm{MA}}(\mathrm{Eu})=$ 3.36 and $\log \mathrm{K}_{\mathrm{MB}}(\mathrm{Eu})=4.98$; (Table 2). The $\Delta \mathrm{LK}_{2 \mathrm{C}}$ and $\Delta \mathrm{LK}_{2 \mathrm{P}}$ values obtained here are 
higher than the $\Delta \mathrm{LK}_{2}$ values reported in Marsac et al. (2010) (denoted as $\Delta \mathrm{LK}_{2}(1)$ in Table 2) for all REE. Hence, HA appears more heterogeneous with respect to REE binding when the constraint of a single $\Delta \mathrm{LK}_{2}$ value is deleted. The $\Delta \mathrm{LK}_{2 \mathrm{C}}$ and $\Delta \mathrm{LK}_{2 \mathrm{P}}$ patterns also differ from the $\Delta \mathrm{LK}_{2}$ patterns given in Marsac et al. (2010). The major change concerns the $\Delta \mathrm{LK}_{2 \mathrm{C}}$ pattern which presents a lower increase for HREE than Marsac et al. (2010) $\Delta \mathrm{LK}_{2}$ (Fig. 1c). This lower increase for HREE is the consequence of both the introduction of REE-phenolic site binding constants that increase from $\mathrm{La}$ to $\mathrm{Lu}$, and the propagation of this increase to the phenolic containing-multidentate site binding constants. As a result, the strong multi-phenolic sites, which depend on $\Delta \mathrm{LK}_{2 \mathrm{P}}$, are no longer constrained to accommodate so much HREE, which explains why the increase in $\Delta \mathrm{LK}_{2 \mathrm{P}}$ for HREE is less pronounced as compared to $\Delta \mathrm{LK}_{2}$ presented in Marsac et al. (2010) (Fig. 2c).

In Model VI, the $\Delta \mathrm{LK}_{2}$ are thought to depend on either the geometry of the carboxylic and phenolic multidentate sites $\left(\Delta \mathrm{LK}_{2}\right.$ accounts for favorable arrangement of the spatial ligands that stabilize REE complexes), or the involvement of additional groups, notably nitrogen-containing groups (Tipping, 1998). Tipping (1998) suggested that $\Delta \mathrm{LK}_{2}$ could be estimated from the metal stability constants with $\mathrm{NH}_{3}$. Therefore, $\Delta \mathrm{LK}_{2}$ is linearly correlated with the stability constant of metal- $\mathrm{NH}_{3}$ complexes in WHAM 6/Model VI. The $\Delta \mathrm{LK}_{2}$ values obtained for the REE using this linear relationship are very low (e.g. 0.29 for Eu), and much lower than the $\Delta \mathrm{LK}_{2}$ values calculated in Marsac et al. (2010), and the $\Delta \mathrm{LK}_{2 \mathrm{C}}$ and $\Delta \mathrm{LK}_{2 \mathrm{P}}$ values obtained in the present study. This may suggest that the participation of N-containing groups only plays a small role in the strong, bi- and tridentate binding sites. The strength of these sites has to be mainly due to the development of favorable spatial arrangements of carboxylic and phenolic ligands as well as the effect of chelation. It is interesting to note that $-15-$ 
345 the high $\Delta \mathrm{LK}_{2 \mathrm{P}}$ values stemming from the new simulations compensate for the decrease in the

$346 \log \mathrm{K}_{\mathrm{MB}}$ values generated by this simulation. Because phenolic groups have high pKa (Ritchie 347 and Perdue, 2003), only a small fraction of the REE is able to bind to monodentate phenolic 348 ligands, as the majority remain bound to specific multidentate, phenol-containing groups.

\subsection{Experimental data fit}

The three experimental datasets used to optimize the Model VI parameters were modeled separately. The results of the simulations with WHAM 6/Model VI and PHREEQC/Model VI are compared in Figure 2 for (i) Eu binding by $\mathrm{HA}$ at $\mathrm{pH} 2$ to 7 and under high metal loading conditions (Pourret et al.'s experimental dataset (2007b); Fig. 2a), (ii) $\mathrm{La}$ and $\mathrm{Lu}$ binding by $\mathrm{HA}$ at $\mathrm{pH}=3$ under variable metal loading conditions (Marsac et al.'s dataset (2010); Fig. 2b), and (iii) Eu binding by HA at pH 6 to 9 with EDTA, and under low metal loading conditions (Sonke and Salters's dataset (2006); Fig. 2c). The quality of the

357 fits can also be evaluated by comparing the measured and simulated REE distribution patterns $358\left(\log \mathrm{K}_{\mathrm{d}}\right)$ for the data of Pourret et al. (2007b) and Marsac et al. (2010) (Figs. 2d and 2e, 359 respectively), or the measured and simulated patterns of the conditional REE-HA stability 360 constants $\left(\log \beta_{\mathrm{HS}}\right)$ for Sonke and Salters' data (2006) (Fig. 2f). The $\log \beta_{\mathrm{HS}}$ values were 361 corrected from the REE-EDTA interaction (Sonke and Salters 2006). The new hypotheses in 362 PHREEQC/Model VI model significantly improve the quality of the fits as the total rmse (i.e. 363 calculated for the whole REE and conditions studied) decreased from 0.10 to 0.07 (Table 2). 364 There is a moderate improvement in the fit for Pourret et al.'s results (2007b) (from 0.10 to 365 0.07), which is primarily seen in high $\mathrm{pH}$ conditions at low metal loading (Figs. 2a and 2d). 366 By contrast, the improvement of the fit is very significant for Sonke and Salters' data (2006), 367 as the rmse is divided by a factor of around 2: 0.10 in the new calculations versus 0.26 in $-16-$ 
WHAM 6/Model VI. This improvement is particularly significant for the LREE at high $\mathrm{pH}$ 369 (e.g. at $\mathrm{pH} 9$ in Fig. $2 \mathrm{f}$ ). The strong overestimation of the $\log \beta_{\mathrm{HS}}$ values obtained for the

370

LREE under this $\mathrm{pH}$ condition with WHAM 6/Model VI is no longer apparent. At a high $\mathrm{pH}$ and low REE/HA ratio, the REE are strongly bound to the HA phenolic groups. The LREE overestimation of the latter with WHAM 6/Model VI is the consequence of the Log $\mathrm{K}_{\mathrm{MA}}-\mathrm{Log}$ $\mathrm{K}_{\mathrm{MB}}$ linear relationship, the HA phenolic sites present high stability constants with LREE. Rmse increases slightly for Marsac et al.'s results (2010), from 0.02 with WHAM 6/Model VI to 0.04 with the new parameters, but remains very low.

\section{DISCUSSION}

The independent optimization of the HA carboxylic and phenolic binding parameters (i.e. removal of the $\log \mathrm{K}_{\mathrm{MA}}-\log \mathrm{K}_{\mathrm{MB}}$ linear relationship and $\Delta \mathrm{LK}_{2}$ dissociation for the carboxylic and phenolic groups) allowed for the first time to satisfactorily and simultaneously model a large set of multi-REE experimental data with the same set of equations and parameters. The following discussion will show that these parameter modifications not only improve the fit of the data, but that the 80 HA sites present REE $\log \mathrm{K}$ patterns that are more consistent with the data available for simple organic ligands (Byrne and Li, 1995). We will also discuss the implications of these parameter modifications on REE speciation of the different HA sites. This was possible for the first time by the introduction of Model VI into PHREEQC.

\subsection{Assessing the consistency of the new modeling parameters}

Figure 3 presents a plot comparing the $\log \mathrm{K}_{\mathrm{Lu}} / \mathrm{K}_{\mathrm{La}}$ ratio, which represent the fractionation of the REE Log K pattern with the average REE stability constants determined 
for (i) 101 organic ligands studied independently (Byrne and Li, 1995) and (ii) the $80 \mathrm{HA}$ 391 sites defined in WHAM 6/Model VI and PHREEQC/Model VI. Since the REE-ligand log K 392 values were available at IS $=0.1 \mathrm{M}$, the REE-HA $\log \mathrm{K}$ values were calculated at $\mathrm{IS}=0.1 \mathrm{M}$ 393 using the Davies equation. The $\log \mathrm{K}_{\mathrm{Lu}} / \mathrm{K}_{\mathrm{La}}$ ratio shows a positive correlation when reported 394 against the average $\mathrm{REE} \log \mathrm{K}$ value $\left(\mathrm{R}^{2}=0.77\right)$. This correlation indicates that the LREE and 395 MREE have more affinity for weak carboxylic ligands, such as acetic acid, than the HREE 396 whereas HREE have more affinity for strong multidentate ligands, such as EDTA, than LREE and MREE. This general increase in the $\log \mathrm{K}_{\mathrm{Lu}} / \mathrm{K}_{\mathrm{La}}$ ratio with increasing stability constants can be used to assess the consistency and accuracy of the new optimized parameters obtained 399 for the $80 \mathrm{HA}$ sites. It is remarkable that the REE-HA $\log \mathrm{K}$ values defined by the new 400 optimized parameters show a similar positive correlation $\left(\mathrm{R}^{2}=0.75\right)$ as do the data for the 101 401 ligands, whereas the parameters obtained in WHAM 6/Model VI lead to a dispersion of the 402 $\log \left(\mathrm{K}_{\mathrm{Lu}} / \mathrm{K}_{\mathrm{La}}\right)$ versus the average stability constants in Figure 3 (no observed correlation). More particularly, because of the $\log \mathrm{K}_{\mathrm{MA}}-\log \mathrm{K}_{\mathrm{MB}}$ linear relationship in WHAM 6/Model VI, strong HA sites (i.e. average REE $\log \mathrm{K}>15$ ) present $\mathrm{K}_{\mathrm{La}}>\mathrm{K}_{\mathrm{Lu}}$, which is not observed among either the 101 organic ligands or the HA sites defined with the new PHREEQC/Model VI parameters. Consequently, PHREEQC/Model VI appears to be more realistic than WHAM 6/Model VI.

\subsection{REE distribution on HA sites}

This section compares the REE speciation on the HA surface obtained using the WHAM 6/Model VI hypotheses (i.e. using the $\log \mathrm{K}_{\mathrm{MA}}-\log \mathrm{K}_{\mathrm{MB}}$ linear relationship and a 411 single and constant $\Delta \mathrm{LK}_{2}$ value for all REE; Tipping, 1998) and the new hypotheses 412 stemming from this study and involved in PHREEQC/Model VI. 
In Model VI, 80 different sites are expected to participate in the cation-HA binding.

414 To simplify the REE speciation on the HA surface, these 80 sites can be gathered in several 415 groups based on two main characteristics: the chemical nature of the ligands (i.e. carboxylic 416 groups: CG, phenolic groups: PG and carboxy-phenolic groups: CPG) and their denticity (i.e. 417 mono-, bi- and tridentate sites).

Figure 4 displays the calculations performed at high metal loading using Pourret et al.'s experimental conditions (2007b), namely $\mathrm{HA}=5 \mathrm{mg} \mathrm{L}^{-1}$, and over a wide $\mathrm{pH}$ range for $\mathrm{La}, \mathrm{Eu}$ and $\mathrm{Lu}$, respectively. At high metal loading, the few strong binding sites play a subordinate role in HA-REE complexation. The criterion that primarily differentiates the two simulations is the chemical nature of the binding sites (i.e. whether they are CG, CPG or PG sites). The WHAM 6/Model VI complexation hypotheses yield very similar speciation results for all of the REE. The complexation is dominated by CPG in each case $\left(\mathrm{La}_{\mathrm{CPG}}=50-80 \%\right.$; $\left.\mathrm{Lu}_{\mathrm{CPG}}=50-60 \%\right)$. The situation is clearly different if the new hypotheses and new modeling parameters are used. The speciation of $\mathrm{La}$ and $\mathrm{Lu}$ is no longer similar. The dominant REE-HA species for $\mathrm{La}$ is $\mathrm{CG}$ ( 80 to $100 \%$ vs. $\mathrm{pH}$ ) instead of CPG when using the equations and parameters of WHAM 6/Model VI. The LREE speciation generated by the new equations and parameters (dominant role of the carboxylic groups) is consistent with the C 1s-NEXAFS analysis of Eu-HA complexes at high metal loading and low $\mathrm{pH}(\mathrm{pH}=5.1)$, which showed that Eu was bound to HA carboxylic sites (Plaschke et al., 2004; Naber et al., 2006). Note that 432 the new equations and parameters do not induce significant changes in Lu-HA speciation. With regards to the effects of site denticity under high metal loading and varying $\mathrm{pH}$ 434 conditions (data not shown), the main consequence of the new equations and parameters is to 435 reduce the relative amount of the REE bound to monodentate sites to almost $0 \%$, whereas it 436 could reach $15 \%$ at $\mathrm{pH}=7$ with the WHAM 6/Model VI parameters. REE-HA binding occurs -19 - 
mainly through bidentate sites (80-90\%) under high metal loading conditions, regardless of the REE and $\mathrm{pH}$. Only a small proportion (10 to $20 \%$, depending on the REE) is bound to the tridentate sites. Another consequence of the new equations and parameters is a drastic decrease of the REE bound to tridentate sites at low metal loading (Marsac et al. 2010; experimental conditions). The WHAM 6/Model VI equations and parameters led to a (i) large increase of the REE bound to HA tridentate sites with decreasing metal loading at $\mathrm{pH}=3$ (20\% at $210^{-2}$ metal loading to $60 \%$ at $410^{-4}$ metal loading for La) (Fig. 5) and (ii) fractionation between $\mathrm{La}$ and $\mathrm{Lu}$ : the relative amount of $\mathrm{La}$ bound to tridentate sites increased much more strongly than that of $\mathrm{Lu}$ with decreasing metal loading. The new equations and parameters clearly modify the REE speciation on HA sites. Firstly, the increase of the REE bound to tridentate sites with decreasing metal loading is less pronounced. Secondly, the amount of La bound to tridentate sites always remains lower than that of $\mathrm{Lu}$ even under very low metal loading. This effect is clearly a consequence of the disappearance of multidentate sites combining REE $\log \mathrm{K}>15$ and $\log \mathrm{K}_{\mathrm{La}}>\log \mathrm{K}_{\mathrm{Lu}}$ in the new modeling strategy, a combination that is totally unrealistic based on Figure 3.

\subsection{Consequences for cation competition}

In natural waters, the REE compete with many other dissolved cations during HA complexation. Among the cations present in natural waters, several cations, such as $\mathrm{Fe}^{3+}$ and $\mathrm{Al}^{3+}$, are known to complex strongly with HA (Tanizaki et al., 1992; Takahashi et al., 1997; Dupré et al., 1999; Olivié-Lauquet et al., 1999; Allard at al., 2004; Tipping et al., 2002; Tipping, 2005; Lofts et al., 2008), and are therefore a strong potential competitor of REE for HA binding. Experimental studies of a single REE (Lippold et al., 2005; 2007) and a modeling study of the whole REE series (Tang and Johannesson, 2003) showed that Al and 
460 Fe could significantly reduce the amount of the REE bound to HA. Therefore, the question to 461 be asked is if metal competition could modify the REE-HA pattern. This cation-REE 462 competition can be accessed through WHAM 6/Model VI simulations. Although the $\log \mathrm{K}_{\mathrm{MA}^{-}}$ $463 \log \mathrm{K}_{\mathrm{MB}}$ linear relationship used in WHAM 6/Model VI implies that all cations will exhibit 464 the same carboxylic to phenolic HA site affinity, the competitive metal tendency to form 465 strong multidentate complexes (simulated by the $\Delta \mathrm{LK}_{2}$ parameter) can modify the REE-HA 466 pattern. For instance, the $\Delta \mathrm{LK}_{2}$ value is equal to 0.46 for $\mathrm{Al}^{3+}$ and 2.2 for $\mathrm{Fe}^{3+}$ (Tipping, 467 1998). Therefore, according to WHAM 6/Model VI's definition of $\mathrm{HA}, \mathrm{Al}^{3+}$ and $\mathrm{Fe}^{3+}$ will 468 compete more efficiently for the LREE and HREE, respectively, since the $\Delta \mathrm{LK}_{2}$ parameter 469 increases from $\mathrm{La}$ to $\mathrm{Lu}$. However, the results obtained here demonstrate that the LREE and 470 HREE are not complexed to the same sites. The LREE are preferentially complexed to 471 carboxylic sites, whereas the HREE are preferably bound to carboxy-phenolic sites (Fig. 4). 472 Therefore, a metal will compete with the REE in different ways depending on whether it complexes itself preferentially with the carboxylic or phenolic sites. This unequal competition

474 will produce REE-HA fractionation patterns that are different from the WHAM 6/Model VI 475 simulations. The occurrence of competing metals with strong affinities for phenolic sites will 476 lead to a release of part of the HREE bound to HA. As part of the HA phenolic groups are 477 unavailable for REE binding, the resulting REE-HA pattern will present the specific feature of 478 carboxylic ligands such as acetic acid (Fig. 1a). Given that competing metals have strong 479 affinities for carboxylic sites, this will lead to a relative decrease in the LREE bound to HA. 480 The resulting REE-HA pattern will present the specific feature of phenolic ligands such as 481 catechol (Fig. 1b). 
To evaluate the expected effects of metal competition on the REE-HA binding 483 patterns, the stability constants of the potential competing metals with acetic acid and catechol were compiled and compared both between them and with the stability constants of the REE (IUPAC, Stability Constants Database). Metals such as $\mathrm{Al}^{3+}$ and $\mathrm{Cu}^{2+}$, with regards to their high affinity for phenol-bearing sites, should preferentially compete with the HREE (Fig. 6). The resulting REE pattern should exhibit a lower increase for HREE than that expected without any competition. Cadmium competition should result in a relative LREE depletion in the REE-HA pattern, as $\mathrm{Cd}^{2+}$ has more affinity for carboxylic groups (assumed to be analogous with acetic acid) than for phenolic groups (assumed to be analogous with catechol) when compared with the average REE. By contrast, $\mathrm{Fe}^{3+}$ competition should not result in a fractionation of the REE-HA pattern since $\mathrm{Fe}^{3+}$ presents a relative affinity for carboxylic and phenolic groups, equal to that of the average REE. Note that the effect of $\mathrm{Al}^{3+}$ and $\mathrm{Fe}^{3+}$ on the REE-HA pattern with regards to their affinity for carboxylic and phenolic ligands is opposed to what is expected with WHAM 6/Model VI. These presumed impacts, though plausible, must nevertheless be viewed with caution: only the affinity for carboxylic and phenolic ligands is discussed here. The metal affinity for multidentate ligands is also a binding mechanism thereby affecting the REE-HA pattern. As compared to the light rare earth elements, heavy rare earth elements are indeed more bound to the HA multidentate sites. Experimental studies should be conducted to confirm if this statement is both true and accurate. The present improvements in the modeling of REE-HA binding will therefore provide a valuable and powerful tool for the interpretation of future experimental results.

These expected effects of metal competition on the REE-HA pattern have two important implications. (i) The change in the REE pattern could provide a way to highlight the occurrence of competing processes. It might even help to clarify the affinity of a given $-22-$ 
metal for the different HA sites. Several studies have shown the difficulty of calibrating cation-HA binding parameters, especially in cation competition experiments. An example of this is Al with the NICA-Donnan model (Kinniburgh et al., 1996). Because Al is a possible groups. However, since $\mathrm{Al}$ is able to compete with $\mathrm{Cd}$ and $\mathrm{Pb}$, Pinheiro et al. (2000) considered that $\mathrm{Al}$ and $\mathrm{Pb}$ were only assigned to be bound with carboxylic groups. Our results

512 suggest that the REE-HA pattern could be used as a probe of the metal affinity for HA binding sites in further REE-metal competition experiments, depending on whether the metal competes with LREE (i.e. a higher affinity for HA carboxylic sites), HREE (i.e. a higher

515 affinity for HA phenolic sites) or every REE. (ii) The REE pattern variability in natural 516 organic-rich waters is generally attributed to the competition between dissolved organic 517 matter (DOM) and carbonate (Elderfield et al., 1990; Tang and Johannesson, 2010). A 518 MREE-enrich pattern is observed when REE binding by DOM dominates, whereas a HREE519 enrich pattern is observed (a REE-carbonate log $\mathrm{K}$ increase from LREE to HREE; Luo and 520 Byrne, 2004) when REE binding by carbonate dominates. However, the LREE and HREE 521 affinity for HA can also vary with regards to the considered metal loading (cation/DOM 522 concentration ratio). Therefore, the present study suggests that not only the metal loading 523 could account for the diversity of the REE patterns in organic-rich waters (Marsac et al., 524 2010), but also the "phenolic" and "carboxylic" competing cations, especially $\mathrm{Al}^{3+}$ and $\mathrm{Fe}^{3+}$.

\section{CONCLUSION}

527 Model VI, coupled with the introduction of two independent $\Delta \mathrm{LK}_{2}$ sets to describe the REE 528 equilibrium complexation with HA low density strong sites, resulted in a strong improvement $-23-$ 
of REE-HA interaction modeling. This new modeling approach allows, for the first time, to simultaneously and satisfactorily model a large set of multi-REE binding to HA experimental data. The increase for $\mathrm{HREE}$ in the $\log \mathrm{K}_{\mathrm{MB}}$ pattern, obtained by removing the linear relationship, is consistent with the phenolic nature of type B sites and REE-catechol binding constants, as cathecol is considered as analogous with phenolic ligands. REE log $\mathrm{K}$ with the

53480 HA sites defined in Model VI, calculated from the newly optimized REE-HA Model VI 535 parameters, are consistent with the REE stability constants for the 101 simple organic ligands, 536 in contrast with the previous data. The introduction of the new Model VI equations and 537 parameters into PHREEQC allows for the first time to highlight the speciation of the REE at 538 the HA surface. The modeling data show that the LREE and HREE are not bound to similar 539 HA sites. The LREE are preferentially bound to carboxylic groups, whereas HREE are 540 preferentially complexed to carboxy-phenolic and phenolic groups. As a consequence, a 541 different REE-HA pattern could arise from competition between cations and REE for HA 542 binding, depending on the cation affinity for these different groups. A survey of available data 543 shows that competition with $\mathrm{Al}^{3+}$ should result in a release of part of the HREE bound to HA, 544 whereas competition with $\mathrm{Fe}^{3+}$ should not have any effect on the REE-HA pattern. Competing 545 cations for phenolic and carboxylic HA sites may therefore account for the diversity of the 546 REE patterns observed in natural organic-rich waters.

547 Further experimental studies have to be conducted to confirm the accuracy of these 548 predictions, which should largely benefit from the performed improvements in the modeling 549 of REE-HA interactions. The PHREEQC/Model VI model set-up provides a valuable and 550 powerful tool for the interpretation of complex REE-competitor metal-HA interactions. The 551 PHREEQC/Model VI coupling should also improve the hydrochemical modeling of the REE 552 since PHREEQC/Model VI accounts for chemical reactions such as mineral $-24-$ 
553 dissolution/precipitation, redox reactions, and the modeling of kinetically-controlled reactions

554 and one-dimensional transport. Finally, it should be highlighted that the new modeling results 555 argue for the development of fine spectroscopic measurements to confirm the exact nature of 556 the HA sites involved in the complexation of the REE by HA.

SUPPORTING INFORMATION AVAILABLE

559 Appendices containing PHREEQC input files, the PHREEQC database used in this study and 560 the detailed calculation of the REE-HA stability constants are available free of charge. In the 561 latter document a method is proposed to introduce another cation in PHREEQC/Model VI.

ACKNOWLEDGEMENTS

564 We thank Dr C. Bruggeman and E. Tipping for their help in the PHREEQC/Model VI 565 coupling. This research was funded by the French ANR, through the "Programme Jeunes 566 Chercheuses - Jeunes Chercheurs"/"SURFREE: Rare earth elements partitioning at solid567 water interface: Impact on REE geochemical behaviour and tracing properties". Dr. Sarah 568 Mullin is acknowledged for post-editing the English style. We thank the two anonymous 569 reviewers and AE, K. H. Johannesson, for their helpful comments.

REFERENCES

572 Allard T., Menguy N., J. Salomon J., Calligaro T., Weber T., Calas G., and Benedetti M. F. 573 (2004) Revealing forms of iron in river-borne material from major tropical rivers of the 574 Amazon Basin (Brazil). Geochim. Cosmochim. Acta 68, 3079-3094.

575 Appelo C. and Postma D. (2005) Geochemistry, groundwater and pollution (2 ${ }^{\text {nd }}$ edition). $576 \quad$ Taylor \& Francis, p. 595. 
577 Bidoglio G., Grenthe I., Qi P., Robouch P. and Omentto N. (1991) Complexation of Eu and Tb with fulvic acids as studied by time-resolved laser-induced fluorescence. Talanta $\mathbf{3 8}$ (9), 999-1008.

Byrne R. H. and Li B. (1995) Comparative complexation behaviour of the rare earth elements. Geochim. Cosmochim. Acta 59, 4575-4589.

Davranche M., Pourret O., Gruau G., Dia A. and Le Coz-Bouhnik M. (2005) Adsorption of REE(III)-humate complexes onto $\mathrm{MnO}_{2}$ : experimental evidence for cerium anomaly and lanthanide tetrad effect suppression. Geochim. Cosmochim. Acta 69, 4825-4835.

Dia A., Gruau G., Olivié-Lauquet G., Riou C., Molénat J. and Curmi P. (2000) The distribution of rare-earths in groundwater: assessing the role of source-rock composition, redox changes and colloidal particles. Geochim. Cosmochim. Acta 64, $4131-4151$.

Dupré L., Viers J., Dandurand J.-L., Polve M., Bénézeth P., Vervier P., and Braun J.-J. (1999) Major and trace elements associated with colloids in organic-rich river waters: Ultrafiltration of natural and spiked solutions. Chem. Geol. 160, 63-80.

592 Elderfield H., Upstill-Goddard R. and Sholkovitz E.R. (1990) The rare earth elements in rivers, estuaries, and coastal seas and their significance to the composition of ocean waters. Geochim. Cosmochim. Acta 54, 971-991.

Gruau G., Dia A., Olivié-Lauquet G., Davranche M. and Pinay G. (2004) Controls on the distribution of rare earth elements in shallow groundwaters. Wat. Res. 38, 3576-3586. Software (acadsoft@bcs.org.uk). 
Johannesson K.H., Tang J., Daniels J.M., Bounds W.J. and Burdige D.J. (2004) Rare earth element concentrations and speciation in organic rich blackwaters of the Great Dismal Swamp, Virginia, USA. Chem. Geol. 209, 271-294.

Kim J.I. and Czerwinski K.R. (1996) Complexation of metal ions with humic acid: metal ion charge neutralisation model. Radiochim. Acta 73, 5-10.

Kinniburgh D. G., van Riemsdijk W. H., Koopal L. K., Borkovec M., Benedetti M. F., and Avena M. J. (1999) Ion binding to natural organic matter: competition, heterogeneity, stoichiometry and thermodynamic consistency. Colloid Surf. A 151, 147-166.

Kinniburgh D.G., Milne C.J., Benedetti M.F., Pinheiro J.P., Filius J., Koopal L. and Van Riemsdijk W.H. (1996) Metal ion binding by humic acid: application of the NICADonnan model. Environ. Sci. Technol. 30, 1687-1698.

Koopal L.K., van Riemsdijk W.H., de Wit J.C.M and Benedetti M.F. (1994) Analytical isotherm equations for multicomponent adsorption to heterogeneous surfaces. J. Coll. Int. Sci. 166, 51-60.

Lippold H., Evans N.D.M., Warwick P. and Kupsch H. (2007) Competitive effect of iron(III) on metal complexation by humic substances: Characterisation of ageing processes. Chemosphere 67, 1050-1056.

Lippold H., Mansel A. and Kupsch H. (2005) Influence of trivalent electrolytes on the humic colloid-borne transport of contaminant metals: competition and flocculation effects. $J$. Contam. Hydro. 76, 337-352.

Liu D.J, Bruggeman C. and Maes N. (2008) The influence of natural organic matter on the speciation and solubility of Eu in Boom Clay porewater. Radiochim. Acta 96, 711-720.

Lofts S., Tipping E. and Hamilton-Taylor J. (2008) The Chemical Speciation of Fe(III) in Freshwaters. Aquat. Geochem. 14, 337-358. 
Luo Y. R. and Byrne R. H. (2004) Carbonate complexation of yttrium and the rare earth elements in natural waters. Geochim. Cosmochim. Acta 68, 691-699.

Marinsky J.A. and Ephraim J. (1986) A unified physicochemical description of the protonation and metal ion complexation equilibria of natural organic acids (humic and fulvic acids). 1. Analysis of the influence of polyelectrolyte properties on protonation equilibria in ionic media: fundamental concept. Environ. Sci. Technol. 20, 349-354.

Marsac R., Davranche M., Gruau G. and Dia A. (2010) Metal loading effect on rare earth element binding to humic acid: Experimental and modelling evidence. Geochim. Cosmochim. Acta 74, 1749-1761.

Milne C.J, Kinniburgh D.G., van Riemsdijk W.H. and Tipping E. (2003) Generic NICADonnan model parameters for metal-ion binding by humic substances. Environ. Sci. Technol. 37, 958-971.

Naber A., Plaschke M., Rothe J., Hofmann H. and Fanghänel T. (2006) S Scanning transmission X-ray and laser scanning luminescence microscopy of the carboxyl group and Eu(III) distribution in humic acid aggregates. J. Electron Spectrosc. Relat. Phenom. $153,71-74$

Olivié-Lauquet G., Allard T., Benedetti M. and Muller J.-P. (1999) Chemical distribution of trivalent iron in riverine material from a tropical ecosystem: a quantitative EPR study. Wat. Res. 33, 2726-2734.

Parkhurst D.L. and Appelo C.A.J. (1999) User's guide to PHREEQC (Version 2) - a computer program for speciation, batch reaction, one-dimensional transport and inverse geochemical calculation. Water-resources Investigation Report 99-4259, USGS, Denver, Colorado, p. 312. 
646 Pédrot M., Dia A., Davranche M., Bouhnik-Le Coz M., Henin O. and Gruau G. (2008) Insights into colloid-mediated trace element release at soil/water interface. J. Coll. Int. Sci. 325, 187-197.

Pinheiro J.P., Mota A.M. and Benedetti M.F. (2000) Effect of aluminum competition on lead and cadmium binding to humic acids at variable ionic strength. Environ. Sci. Technol.

652

664

665

666 34, 5137-5143.

Plaschke M., Rothe J., Denecke M. A. and Fanghänel T. (2004) Soft X-ray spectromicroscopy of humic acid europium(III) complexation by comparison to model substances. $J$. Electron Spectrosc. Relat. Phenom. 135, 53-65.

Pourret O., Davranche M., Gruau G. and Dia A. (2007a) Organic complexation of rare earth elements in natural waters: evaluating model calculations from ultrafiltration data. Geochim. Cosmochim. Acta 71, 2718-2735.

Pourret O., Davranche M., Gruau G. and Dia A. (2007b) Rare earth complexation by humic acid. Chem. Geol. 243, 128-141.

Ritchie J.D. and Perdue E.M. (2003) Proton-binding study of standard and reference fulvic acids, humic acids, and natural organic matter. Geochim. Cosmochim. Acta 67, 85-96.

Sasaki T., Kobayashi T., Tagagi I. and Moriyama H. (2008) Discrete fragment model for complex formation of europium(III) with humic acid. J. Nucl. Sci. Technol. 45(8), 718724.

Sonke J.E. (2006) Lanthanide-humic substances complexation. II. Calibration of humic ionbinding model V. Environ. Sci. Technol. 40, 7481-7487.

Sonke J.E. and Salters V.J.M. (2006) Lanthanide-humic substances complexation. I. Experimental evidence for a lanthanide contraction effect. Geochim. Cosmochim. Acta 70, 1495-1506. 
Takahashi Y., Minai Y., Ambe S., Makide Y., Ambe F. and Tominaga T. (1997) Simultaneous determination of stability constants of humate complexes with various metal ions using multitracer technique. Sci. Tot. Environ. 198, 61-71.

Tang J. and Johannesson K.H. (2003) Speciation of rare earth elements in natural terrestrial waters: assessing the role of dissolved organic matter from the modeling approach. Geochim. Cosmochim. Acta 67, 2321-2339.

Tang J. and Johannesson K.H. (2010) Ligand extraction of rare earth elements from aquifer sediments: Implications for rare earth element complexation with organic matter in natural waters. Geochim. Cosmochim. Acta 74, 6690-6705.

Tanizaki Y., Shimokawa T., and Nakamura M. (1992) Physicochemical speciation of trace elements in river waters by size fractionation. Environ. Sci. Technol. 26, 1433-1444.

Tipping E. (1998) Humic ion-binding model VI: an improved description of the interactions of protons and metal ions with humic substances. Aquat. Geochem. 4, 3-48.

Tipping E. (2005) Modelling Al competition for heavy metal binding by dissolved organic matter in soil and surface waters of acid and neutral pH. Geoderma 127, 293-304.

Tipping E. and Hurley M.A. (1992) A unifying model of cation binding by humic substances. Geochim. Cosmochim. Acta 56, 3627-3641.

Tipping E., Rey-Castro C., Bryan S. E., and Hamilton-Taylor J. (2002) Al(III) and Fe(III) binding by humic substances in freshwaters and implications for trace metal speciation. Geochim. Cosmochim. Acta 66, 3211-3224.

Viers J., Dupré B., Polvé M., Schott J., Dandurand J.-L. and Braun J.J. (1997) Chemical weathering in the drainage basin of a tropical watershed (Nsimi-Zoetele site, Cameroon): comparison between organic poor and organic-rich waters. Chem. Geol. 140, 181-206. 
694 Yamamoto Y., Takahashi Y. and Shimizu H. (2010) Systematic change in relative stabilities of REE-humic complexes at various metal loading levels. Geochem. J. 44, 39-63.

696

697

698 Table and Figure Captions

699

700 Table 1. Parameters used in this study to model REE binding by humic acid.

701

702

Table 2. $\log \mathrm{K}_{\mathrm{MA}}, \log \mathrm{K}_{\mathrm{MB}}, \Delta \mathrm{LK}_{2 \mathrm{C}}$ and $\Delta \mathrm{LK}_{2 \mathrm{P}}$ values fitted from the experimental data using PHREEQC/Model VI. The quality of the fit is determined by the rmse, calculated as $\sqrt{\text { mean }\left(\log v_{\text {exp }}-\log v_{\text {calc }}\right)^{2}}$, where $v$ is the amount of REE bound to HA per gram of DOC for the experimental and modeled data, respectively. The $\log \mathrm{K}_{\mathrm{MA}}, \log \mathrm{K}_{\mathrm{MB}}, \Delta \mathrm{LK}_{2}$ (where $\Delta \mathrm{LK}_{2}=\Delta \mathrm{LK}_{2 \mathrm{C}}=\Delta \mathrm{LK}_{2 \mathrm{P}}$ ) data published by Marsac et al. (2010) using WHAM 6/Model VI are shown for comparison.

708

Figure 1. Comparison of the REE patterns for the HA binding parameters obtained by Marsac et al. (2010) with WHAM 6/Model VI and the patterns obtained with PHREEQC/Model VI:

711 (a) $\log \mathrm{K}_{\mathrm{MA}}$ compared with $\log \mathrm{K}$ (REE-acetic acid), (b) $\log \mathrm{K}_{\mathrm{MB}}$ compared with $\log \mathrm{K}$ (REE-

712 catechol) and (c) $\Delta \mathrm{LK}_{2 \mathrm{C}}$ and $\Delta \mathrm{LK}_{2 \mathrm{P}}$ (this study) compared with $\Delta \mathrm{LK}_{2}$ (Marsac et al., 2010; $\left.\Delta \mathrm{LK}_{2}=\Delta \mathrm{LK}_{2 \mathrm{C}}=\Delta \mathrm{LK}_{2 \mathrm{P}}\right)$ 
715 Figure 2. Comparison between published experimental data for REE binding with HA and 716 the results of simulations of the same data using WHAM 6/Model VI and PHREEQC/Model

717 VI, respectively. The experimental data are from Pourret et al. (2007b) (a), Marsac et al. 718 (2010) (b) and Sonke and Salters (2006) (c). The "patterns shown" correspond to the REE-HA 719 patterns, presented for the experiments demarcated with an open symbol, in (d), (e) and (f).

721 Figure 3. $\log \left(\mathrm{K}_{\mathrm{Lu}} / \mathrm{K}_{\mathrm{La}}\right)$ versus the average REE $\log \mathrm{K}_{\mathrm{REE}}$ values obtained for 101 organic 722 ligands (Byrne and Li, 1995) and for the 80 ligands defined in WHAM 6/Model VI and PHREEQC/Model VI. Log $\left(\mathrm{K}_{\mathrm{Lu}} / \mathrm{K}_{\mathrm{La}}\right)$ is used as an indicator of the REE-ligand pattern. The linear regression for the 101 organic ligands (Byrne and Li, 1995) and for the $80 \mathrm{HA}$ sites obtained here with PHREEQC/Model VI are also presented.

Figure 4. Speciation calculation results for $\mathrm{La}(\mathrm{a}), \mathrm{Eu}(\mathrm{b})$ and $\mathrm{Lu}$ (c) depending on the complexation hypotheses used. The simulated experimental data are those from Pourret et al. (2007b). CG: carboxylic groups; CPG: carboxy-phenolic groups; PG: phenolic groups.

Figure 5. The proportion of $\mathrm{La}$ and $\mathrm{Lu}$ bound to tridentate sites versus the REE/HA ratios. The displayed evolutions depend on whether the new equations and parameters or those formerly installed in WHAM6/ModelVI are used. The simulated experimental data are from Marsac et al. (2010).

Figure 6. Literature compilation of metal-acetic acid or -catechol binding constants. The straight line passing through the mean REE value indicates metals that should not compete differently with the LREE and MREE. Conversely, metals below this line, such as $\mathrm{Cd}^{2+}$, -32 - 
739 should compete primarily with the LREE, whereas those above this line, such as $\mathrm{Al}^{3+}$, should 740 be mainly in competition with the HREE. Data sources: IUPAC Stability constants database. 741 


\begin{tabular}{|c|c|c|}
\hline Parameter & Description & Values \\
\hline $\mathrm{n}_{\mathrm{A}}$ & Amount of type A sites $\left(\mathrm{mol} \mathrm{g}^{-1}\right)$ & $3.310^{-3}$ \\
\hline $\mathrm{n}_{\mathrm{B}}$ & Amount of type B sites $\left(\mathrm{mol} \mathrm{g}^{-1}\right)$ & $0.5 \times \mathrm{n}_{\mathrm{A}}$ \\
\hline $\mathrm{pK}_{\mathrm{A}}$ & Intrinsic proton dissociation constant for type A sites & 4.1 \\
\hline $\mathrm{pK}_{\mathrm{B}}$ & Intrinsic proton dissociation constant for type B sites & 8.8 \\
\hline$\Delta \mathrm{pK}_{\mathrm{A}}$ & Distribution term that modifies $\mathrm{pK}_{\mathrm{A}}$ & 2.1 \\
\hline$\Delta \mathrm{pK}_{\mathrm{B}}$ & Distribution term that modifies $\mathrm{pK}_{\mathrm{B}}$ & 3.6 \\
\hline \multirow{2}{*}{$\log \mathrm{K}_{\mathrm{MA}}$} & Intrinsic equilibrium constant for metal binding at type & Fitted \\
\hline & A sites & experimental data \\
\hline \multirow{2}{*}{$\log \mathrm{K}_{\mathrm{MB}}$} & Intrinsic equilibrium constant for metal binding at type & Fitted \\
\hline & B sites & experimental data \\
\hline$\Delta \mathrm{LK}_{1}$ & Distribution term that modifies $\log \mathrm{K}_{\mathrm{MA}}$ and $\log \mathrm{K}_{\mathrm{MB}}$ & 2.8 \\
\hline$\Delta \mathrm{LK}_{2}$ & $\begin{array}{l}\text { Distribution term that modifies the strengths of } \\
\text { bidentate and tridentate sites }\end{array}$ & $\begin{array}{l}\text { Fitted from } \\
\text { experimental data }\end{array}$ \\
\hline SA & HA surface area $\left(\mathrm{m}^{2} \mathrm{~g}^{-1}\right)$ & $\begin{array}{l}\text { Fitted from WHAM } \\
\text { 6/Model VI simulations }\end{array}$ \\
\hline$\kappa$ & Debye-Hückel parameter (m) & $\left(3.29 \times 109 \times \mathrm{I}^{1 / 2}\right)^{-1}$ \\
\hline
\end{tabular}

743 


\begin{tabular}{cccccccccc}
\hline $\mathrm{REE}$ & $\log \mathrm{K}_{\mathrm{MA}}^{(1)}$ & $\log \mathrm{K}_{\mathrm{MA}}^{(2)}$ & $\log \mathrm{K}_{\mathrm{MB}}^{(1)}$ & $\log \mathrm{K}_{\mathrm{MB}}^{(2)}$ & $\Delta \mathrm{LK}_{2}^{(1)}$ & $\Delta \mathrm{LK}_{2 \mathrm{C}}^{(2)}$ & $\Delta \mathrm{LK}_{2 \mathrm{P}}^{(2)}$ & rmse $^{(1)}$ & rmse $^{(2)}$ \\
\hline $\mathrm{La}$ & 2.70 & 3.29 & 8.00 & 4.39 & 1.10 & 2.01 & 4.39 & 0.09 & 0.07 \\
$\mathrm{Ce}$ & 2.72 & 3.34 & 8.07 & 4.54 & 1.15 & 2.02 & 4.43 & 0.08 & 0.06 \\
$\mathrm{Pr}$ & 2.73 & 3.36 & 8.10 & 4.69 & 1.20 & 2.06 & 4.46 & 0.07 & 0.05 \\
$\mathrm{Nd}$ & 2.74 & 3.37 & 8.14 & 4.76 & 1.20 & 2.06 & 4.46 & 0.08 & 0.05 \\
$\mathrm{Sm}$ & 2.75 & 3.39 & 8.17 & 4.90 & 1.30 & 2.09 & 4.54 & 0.08 & 0.05 \\
$\mathrm{Eu}$ & 2.74 & 3.36 & 8.14 & 4.98 & 1.35 & 2.10 & 4.57 & 0.08 & 0.05 \\
$\mathrm{Gd}$ & 2.72 & 3.33 & 8.07 & 4.99 & 1.35 & 2.10 & 4.57 & 0.10 & 0.06 \\
$\mathrm{~Tb}$ & 2.71 & 3.30 & 8.04 & 5.03 & 1.50 & 2.12 & 4.68 & 0.11 & 0.06 \\
$\mathrm{Dy}$ & 2.70 & 3.27 & 8.00 & 5.06 & 1.60 & 2.14 & 4.75 & 0.12 & 0.07 \\
$\mathrm{Ho}$ & 2.69 & 3.24 & 7.97 & 5.09 & 1.65 & 2.16 & 4.79 & 0.14 & 0.08 \\
$\mathrm{Er}$ & 2.69 & 3.25 & 7.97 & 5.09 & 1.70 & 2.17 & 4.82 & 0.15 & 0.09 \\
$\mathrm{Tm}$ & 2.67 & 3.22 & 7.90 & 5.14 & 1.90 & 2.22 & 4.97 & 0.15 & 0.09 \\
$\mathrm{Yb}$ & 2.65 & 3.19 & 7.83 & 5.18 & 2.05 & 2.26 & 5.08 & 0.15 & 0.10 \\
$\mathrm{Lu}$ & 2.64 & 3.16 & 7.80 & 5.23 & 2.10 & 2.31 & 5.11 & 0.16 & 0.10 \\
$\mathrm{Mean}$ & 2.70 & 3.29 & 8.02 & 4.93 & 1.51 & 2.13 & 4.69 & 0.11 & 0.07 \\
\hline
\end{tabular}

$748 \quad$ (1) Marsac et al. (2010)

749 (2) This study

750

751

Table 2

752 

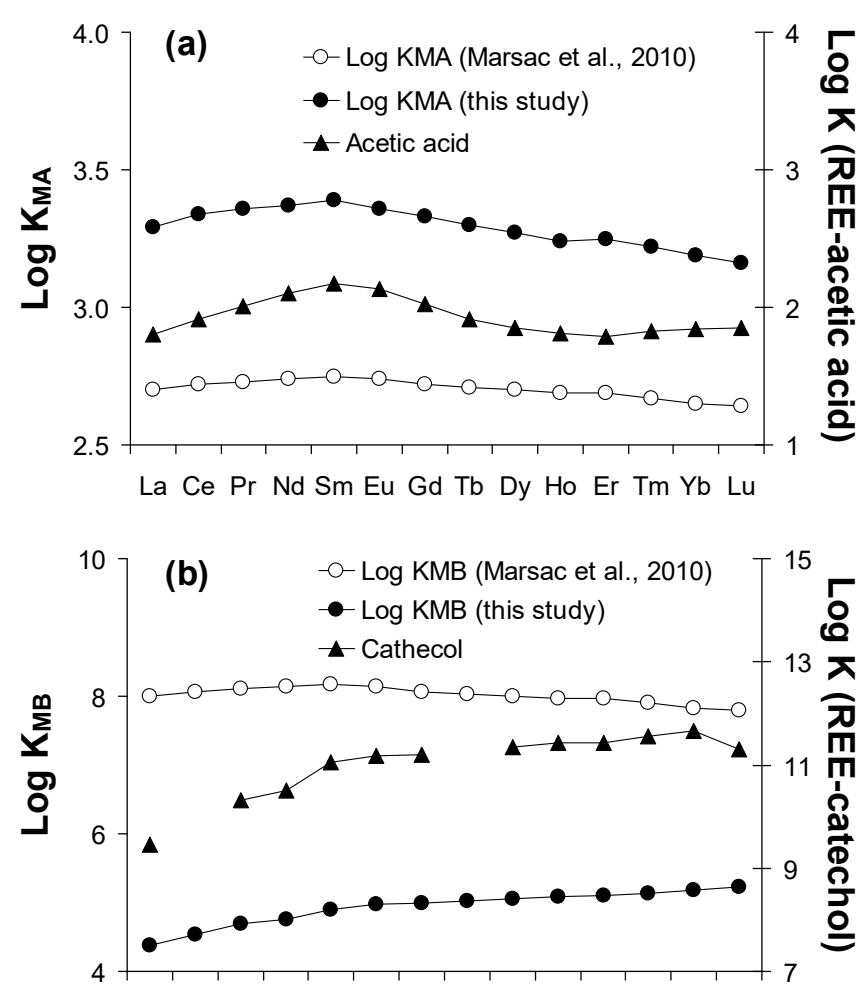

La Ce Pr Nd Sm Eu Gd Tb Dy Ho Er Tm Yb Lu

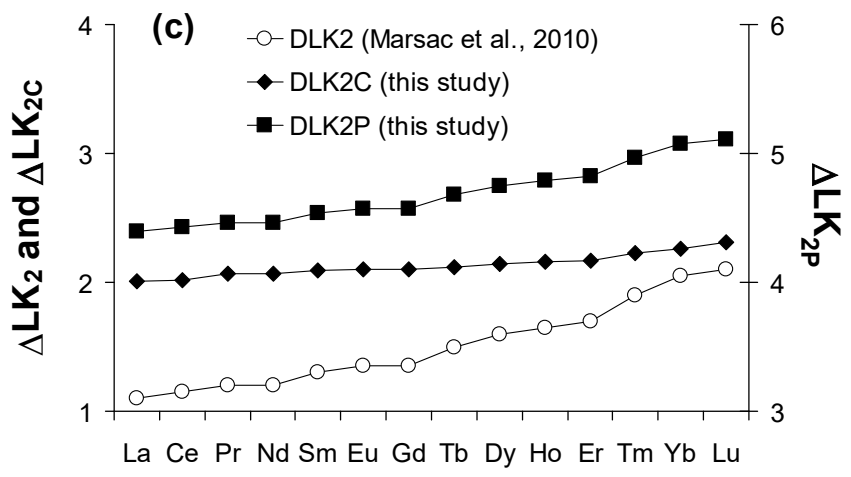



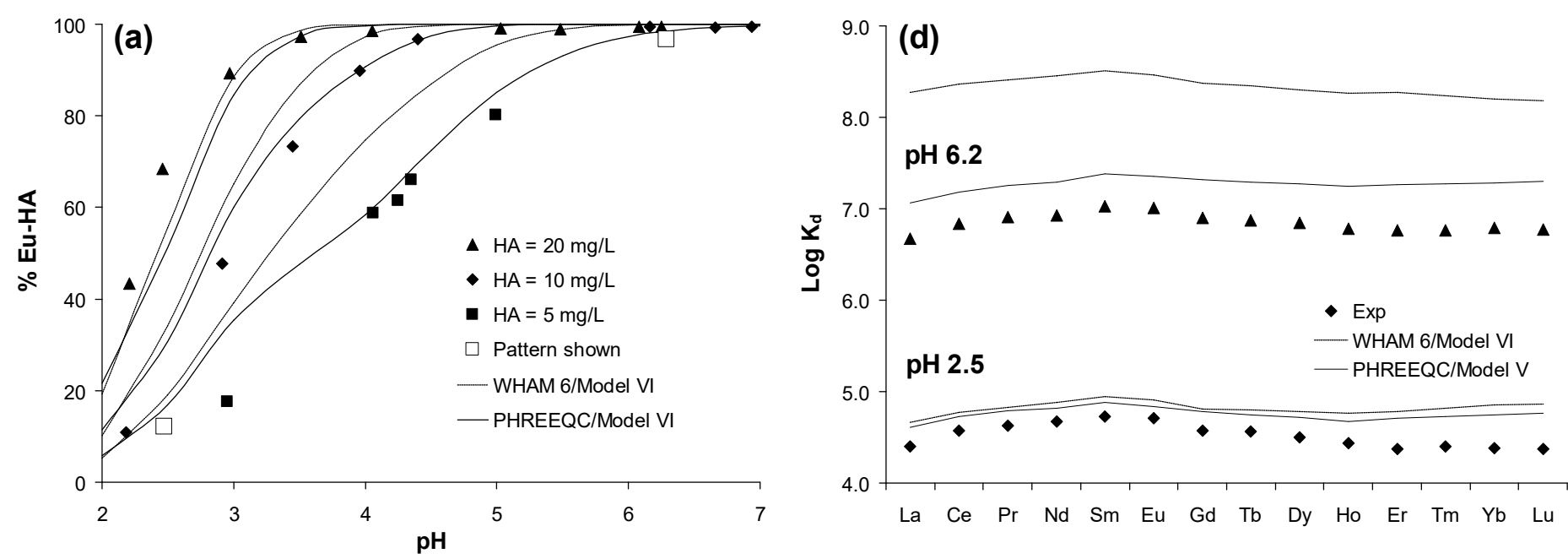

-4.07 (b)
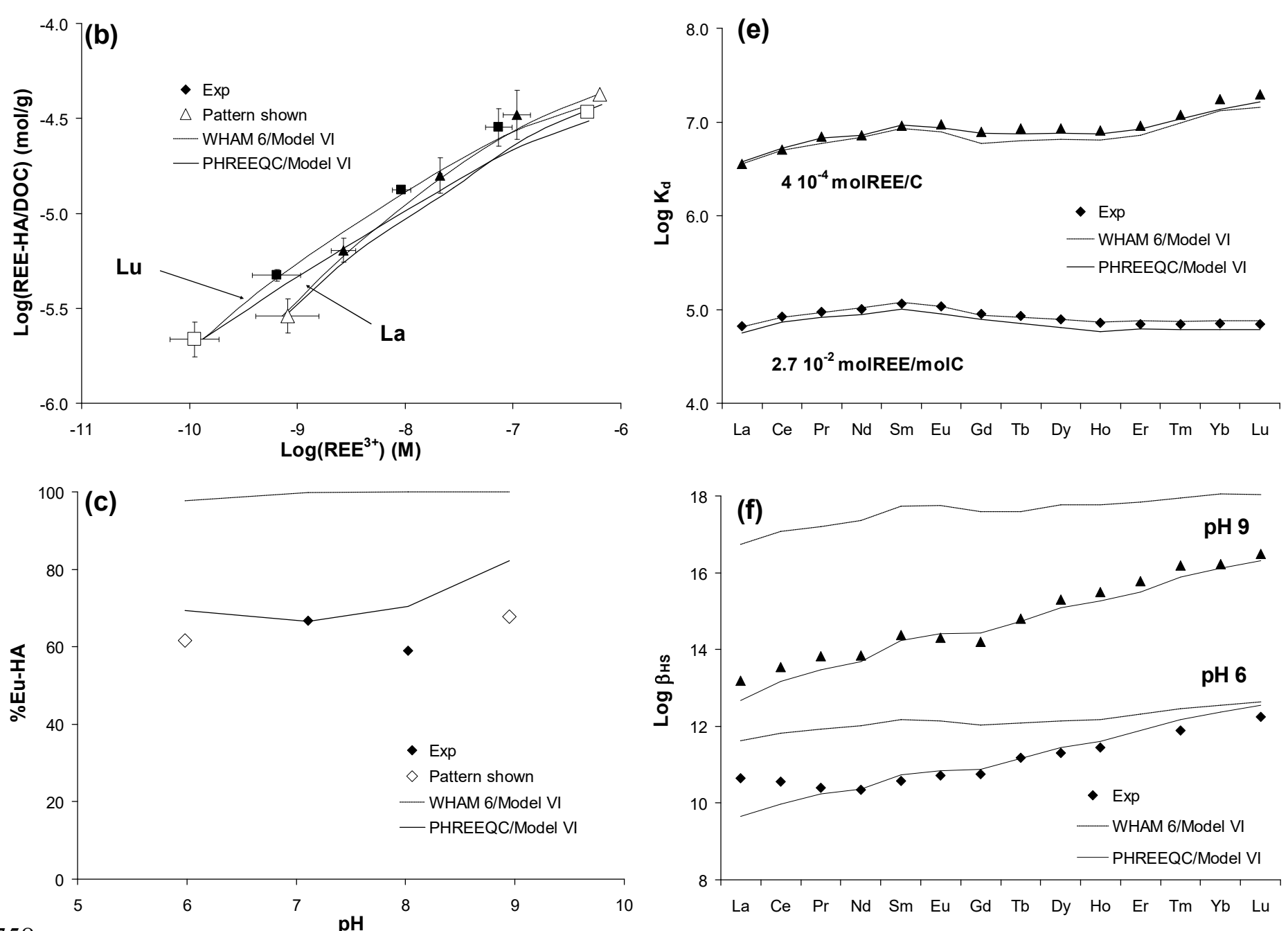

758

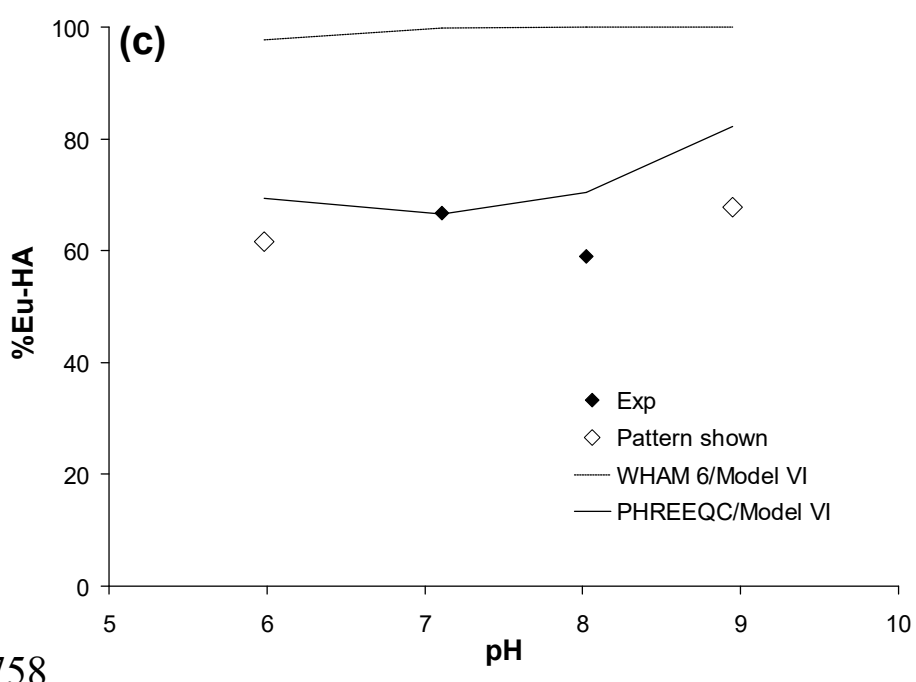

759

760 
Figure 2

762

$-38-$ 


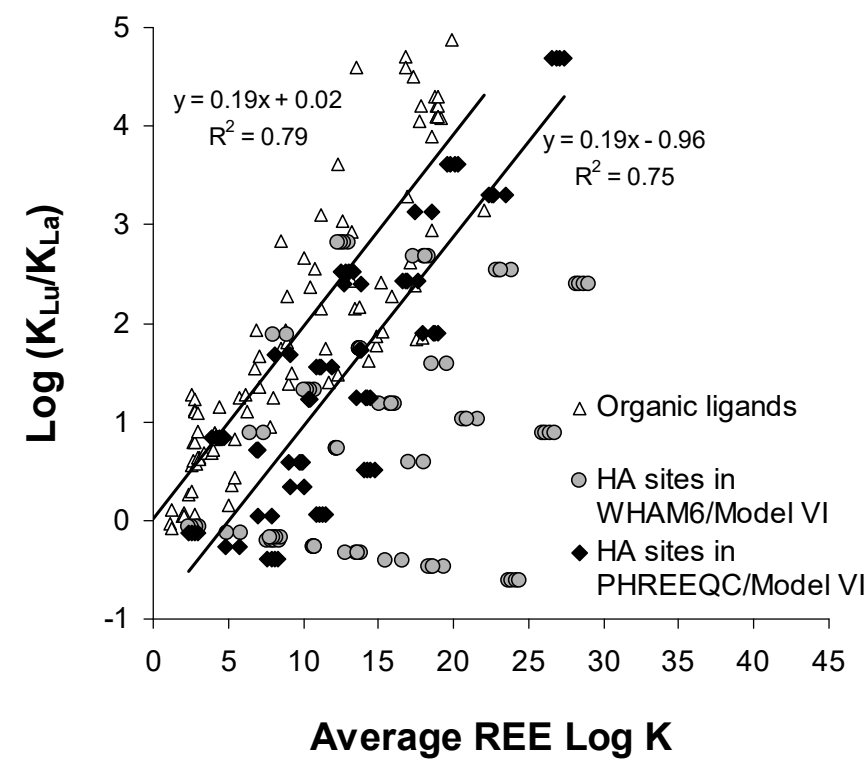

763

764

765

766

Figure 3

767 

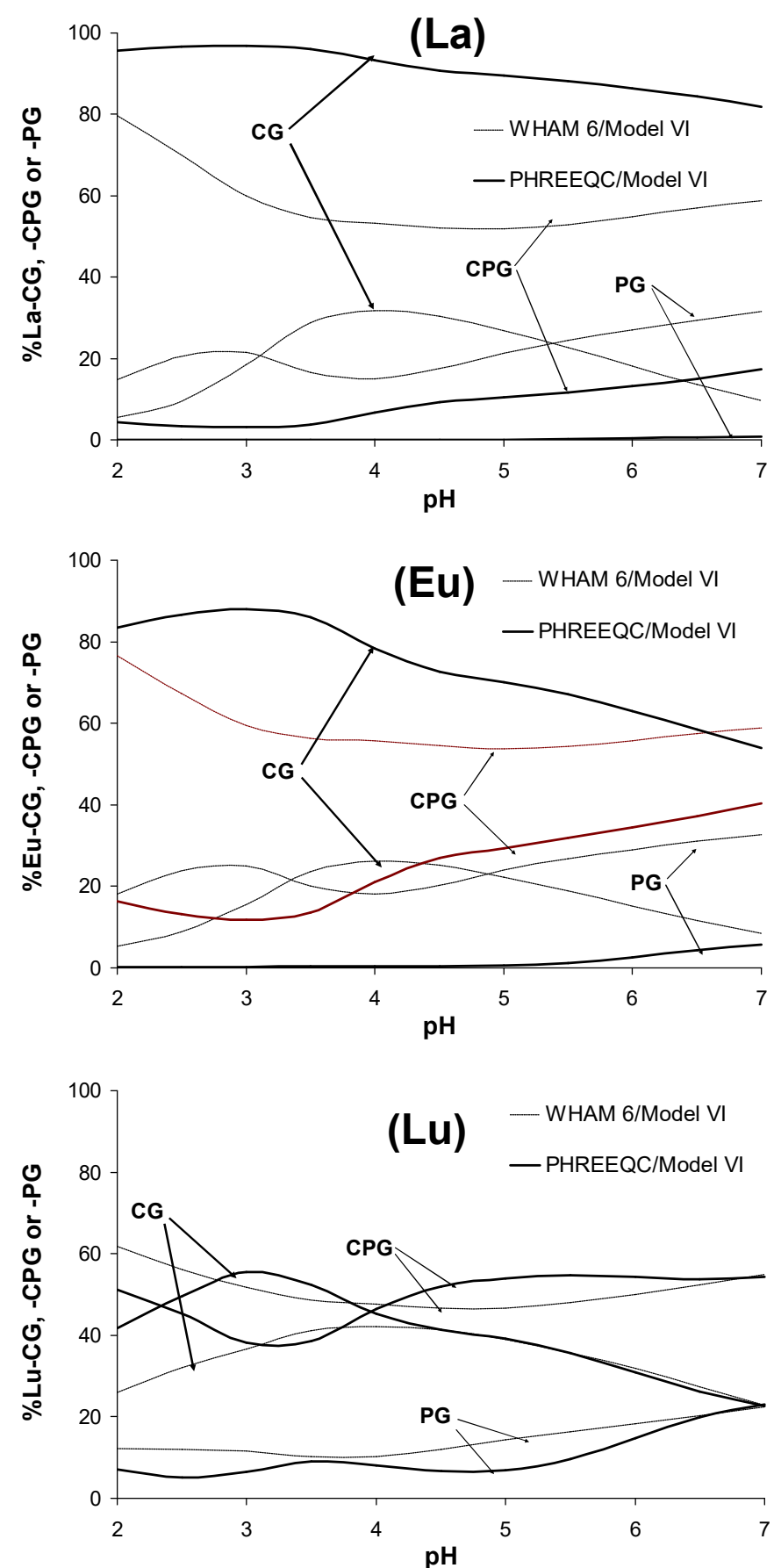


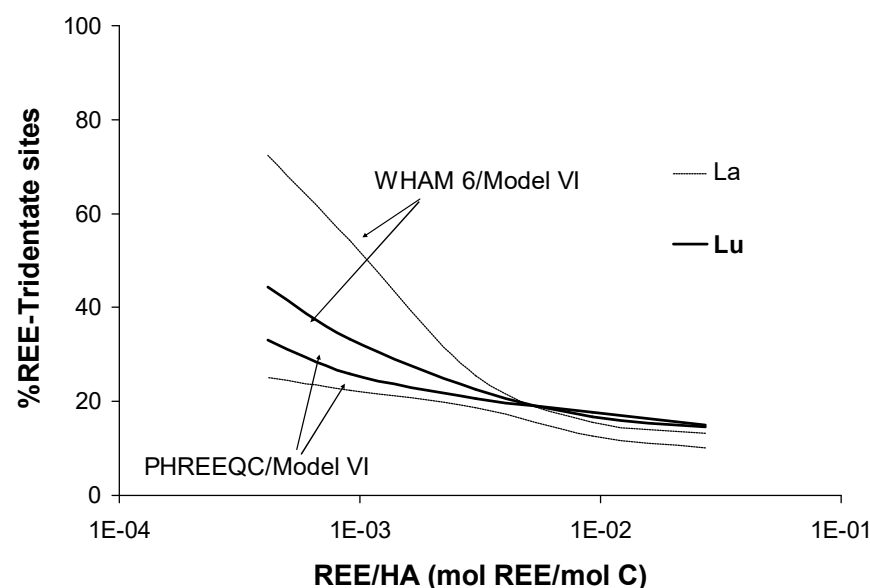

773

774

775

Figure 5

776

777

778

- 41 - 
780

781

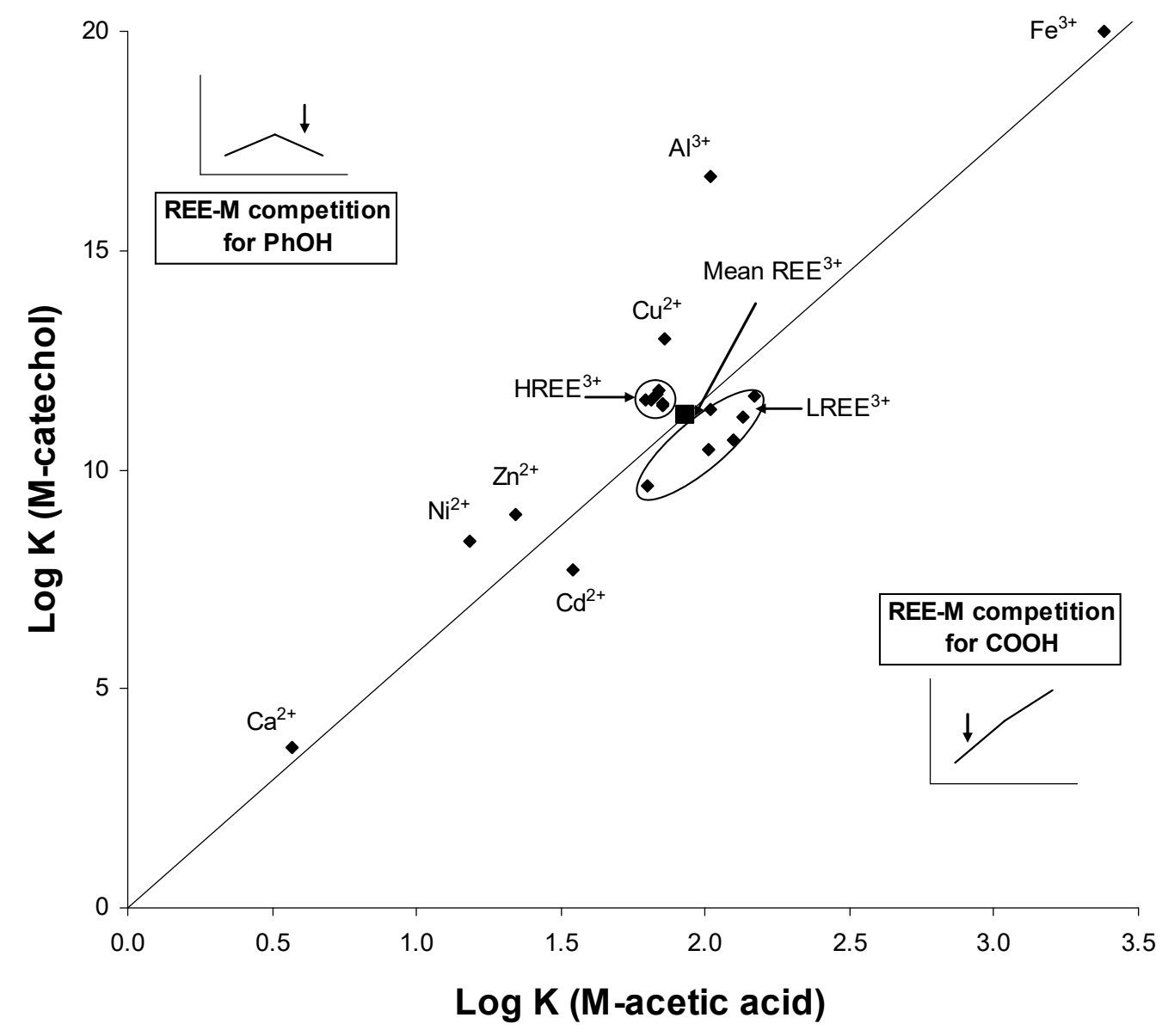

782

783

784

785

Figure 6

786

- 42 - 